\title{
Penggunaan Database Mysql dengan Interface PhpMyAdmin sebagai Pengontrolan Smarthome Berbasis Raspberry Pi
}

\author{
Rizky Fajar Ramadhan"1, Riki Mukhaiyar ${ }^{2}$ \\ 1.2 Jurusan Teknik Elektro, Fakultas Teknik, Universitas Negeri Padang \\ Jl. Prof Dr. Hamka Air Tawar, Padang, Indonesia \\ 06rizkyramadhan@gmail.com ${ }^{1}$, riki.mukhaiyar@yahoo.co.uk ${ }^{2}$
}

\begin{abstract}
The use of Smarthome in modern times like this is very efficient for controlling household devices and appliances. To make this control, an application platform is needed as a bridge to access the system that has been designed on the Smarthome. In its use, the database requires a server to store data, where the server must be rented per month and incur large costs. Therefore, the MySQL database system uses the Raspberry Pi as the main server. Where the Raspberry Pi used will be set to become a public server so that it can be accessed freely via a device connected to the internet wherever the user is, accessing this database only uses public dns with the phpMyAdmin interface on a web browser, for example: raspibroker.ddns.net/phpMyAdmin. The result is that the use of this database does not need to rent a server so that it can be accessed by users via devices that have internet access because server usage has been overcome through making a public server using the Raspberry Pi, besides making it easier for users to access the system using the public server from the Raspberry Pi it also saves funds.
\end{abstract}

Keywords-SmartHome, MySQL, phpMyAdmin, Raspberry Pi.

Abstrak - Penggunaan Smarthome pada masa modern seperti ini sangat efisien untuk mengendalikan perangkat dan alatalat rumah tangga. Untuk membuat suatu pengendalian tersebut, dibutuhkan sebuah platform aplikasi sebagai jembatan untuk mengakses sistem yang telah dirancang pada Smarthome tersebut. Dalam penggunaanya database tersebut memerlukan server untuk menyimpan data, dimana server tersebut harus disewa perbulannya dan mengeluarkan biaya yang besar. Maka dari itu sistem penggunaan database MySQL dengan menggunakan Raspberry Pi sebagai server utama. Dimana Raspberry Pi yang digunakan akan diatur untuk menjadi server publik sehingga bisa diakses secara bebas melalui perangkat yang tersambung dengan internet dimanapun user berada, pengaksesan database ini hanya menggunakan dns public dengan interface phpMyAdmin pada web browser contohnya: raspibroker.ddns.net/phpMyAdmin. Hasilnya penggunaan database tersebut tidak perlu penyewaan server agar bias diakses oleh user melalui perangkat yang memiliki akses internet karena penggunaan server telah diatasi melalui pembuatan server public menggunakan Raspberry $\mathrm{Pi}$, selain memudahkan user dalam mengakses system penggunaan server public dari Raspberry $\mathrm{Pi}$ juga menghemat dana.

Kata kunci-SmartHome, MySQL, phpMyAdmin, Raspberry Pi.

\section{Pendahuluan}

Penggunaan Perangkat Smarthome pada masa ini sudah hampir banayak digunakan di seluruh dunia. Pada dasarnya Smarthome adalah suatu home automation atau rumah otomatis yang menggabungkan antara teknologi beserta layanan yang dikhusukan untuk sebuah rumah, contoh yang paling lazim adalah mengontrol perangkat dari jarak jauh, seperti mengontrol sebuah penghidupan lampu, dan pemonitoringan sebuah kamera pengaman. Pengontrolan yang dilakukan bertujuan untuk mencapai kenyamanan dan keamanan bagi pemilik rumah [1][2].

Untuk membuat sebuah perangkat Smarthome ini tentunya tidak lupa dibarengi dengan pembuatan database untuk menyimpan data pemilik rumah agar keamanan dari "Smarthome" ini meningkat. Database tersebut akan dipadukan dengan sebuah aplikasi yang terhubung ke system dalam Smarthome. Selain memudahkan pemilik rumah untuk mengakses system dari Smarthome tersebut melalui aplikasi, tentunya database ini pun akan menjamin keamanan dari sang pemilik Smarthome tersebut

Database sendiri adalah sebuah system untuk menyimpan kumpulan data yang terorganisir baik 1 pengguna ataupun lebih dalam bentuk digital[3]. MySQL dipilih karena memiliki beberapa keunggulan diantaranya adalah software open source yang artinya dapat digunakan secara gratis, Keamanan yang tinggi, Multi User yang artinya dapat digunakan oleh beberapa pengguna secara bersamaan, dan kefleksibelan antar muka (interface) pada beberapa aplikasi dan bahasa pemrograman [4].

Tujuan utama dari pengembangan tugas akhir ini adalah membuat keamanan yang lebih terjaga dalam system Smarthome menggunakan MySQL dan phpMyAdmin sebagai tambahan platform pengaman yang 
digunakan oleh user untuk mengakses Smarthome melalui aplikasi yang dimiliki oleh user dan terhubung ke server yang ada di Smarthome. Dimana MySQL disini bekerja sebagai database server, sedangkan phpMyAdmin sebagai interface untuk memudahkan mengakses manajemen MySQL[3].

\section{Database}

Database : Database adalah sebuah system yang di buat untuk mengorganisasi, menyimpan dan menarik data dengan mudah. Database terdiri dari kumplan data yang terorganisir untuk 1 atau lebih penggunaan, dalam bentuk digital. Database digital di manage menggunakan Database Management System (DBMS), yang menyimpan isi database, mengizinkan pembuatan dan maintenance data dan pencarian dan akses yang lain. Beberapa Database yang ada saat ini adalah : Mysql, Sql Server, Ms.Access, Oracle, dan PostgreSql[3].

Adapun beberapa fungsi dari database adalah

1. Mempermudah identifikasi data dengan cara pengelompokkan data, salah satu contoh nya dengan pembuatan beberapa tabel atau field yang berbeda-beda.

2. Meminimalisir suatu data ganda.

3. Mempermudah penggunaan user dalam berbagai hal, misalnya pada saat peng-inputan data baru.

4. Penyimpanan secara digital

5. menjadi alternatif lain terkait masalah penyimpanan ruang dalam suatu aplikasi.

Adapun beberapa jenis database, diantaranya

1. Operational Database

Database jenis ini mengoperasikan penyimpanan data yang sangat rinci agar dapat dengan mudah digunakan. Database ini biasa digunakan untuk database pelanggan.

2. Relational Database

Pada database ini, user dapat mengakses atau mencari informasi dalam tabel yang berbeda beda.

3. Distributed Database

Untuk database jenis ini dapat mendistribusikan data - data secara tersebar namun saling berhubungan serta dapat diakses secara bersama - sama.

4. External Database

Database terakhir ini sering digunakan sebagai keperluan komersial karena kemudahan mengaksesnya yang memang dikhususkan untuk publik.

Dari penjelasan diatas untuk database yang digunakan adalah jenis Relational Database yang dikhusukan untuk perorangan,
SQL (Structured Query Language) adalah sebuah bahasa scripting yang dipergunakan untuk mengolah database. Database besar seperti Mysql, PostgreSQL dan SQL Server sudah menggunakan SQL untuk mengolah database nya. SQL yang di pergunakan software database tersebut adalah sama kecuali sedikit perbedaan di beberapa tempat[3][4]. Pada tugas akhir ini penulis menggunakan MySQL sebagai platform pengoperasian SQL ini.

MySQL adalah salah satu jenis database server yang sangat terkenal. MySQL menggunakan bahasa SQL untuk mengakses database nya. Lisensi Mysql adalah FOSS License Exception dan ada juga yang versi komersial nya. Tag Mysql adalah "The World's most popular open source database". MySQL tersedia untuk beberapa platform, di antara nya adalah untuk versi windows dan versi linux. Untuk melakukan administrasi secara lebih mudah terhadap Mysql, anda dapat menggunakan software tertentu, di antara nya adalah phpmyadmin dan mysql yog.[3][5].

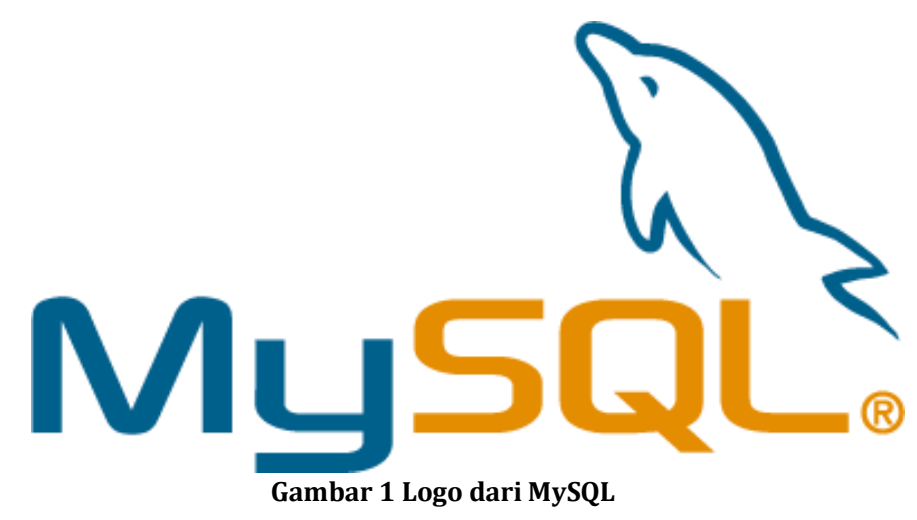

\section{phpMyAdmin}

PhpMyAdmin adalah sebuah aplikasi atau perangkat berbasis opensource yang bisa kita gunakan secara gratis untuk mealakukan pemrograman ataupun administrasi pada database MySQL. PhpMyAdmin sendiri menggunakan bahasa PHP untuk pemrogramannya[6], selain itu phpMyAdmin mendukung berbagai operasi MySQL, diantaranya (mengelola basis data, tabel-tabel, bidang (fields), relasi (relations), indeks, pengguna (users), perijinan (permissions), dan lainlain.

Jadi dapat disimpulkan pula bahwa phpMyAdmin berbeda dengan MySQL. Dimana PhpMyAdmin digunakan sebagai alat yang memudahkan dalam pengoperasian database MySQL, sedangkan MySQL adalah suatu database itu sendiri, dimana database berfungsi sebagai penyimpanan data[7][8]. 


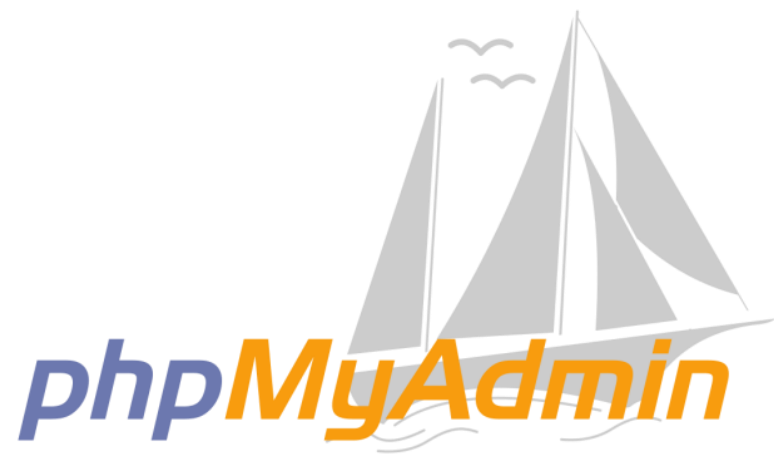

Gambar 2 Logo dari phpMyAdmin

\section{Metode}

Metode yang digunakan dalam penelitian ini adalah studi literatur dan penelitian eksperimen. Dimana studi literatur digunakan untuk mendapatkan sumber bacaan yang terpercaya dari beberapa jurnal yang digunakan dalam penelitian sedangkan pengimplementasiannya digunakanlah metode penelitian eksperimen.

Dalam Pengimplementasiannya aplikasi yang sudah dibuat akan dihubungkan ke database MySQL melalui phpMyAdmin hal ini dilakukan untuk mengamankan data dari user sekaligus Smarthome yang akan dikontrol.

\section{Perancangan Sistem}

Berdasarkan penjelasan singkat diatas maka perancangan system meliputi beberapa tahapan diantaranya, Perancangan Perangkat Keras (Hardware) dan Perancangan Perangkat Lunak (Software).

\section{Perancangan Perangkat Keras (Hardware)}

Dalam pembuatannya pengontrolan rumah pintar (Smarthome) memerlukan beberapa dari komponen perangkat keras. Berikut diagram blok dari system perangkat keras yang akan digunakan.

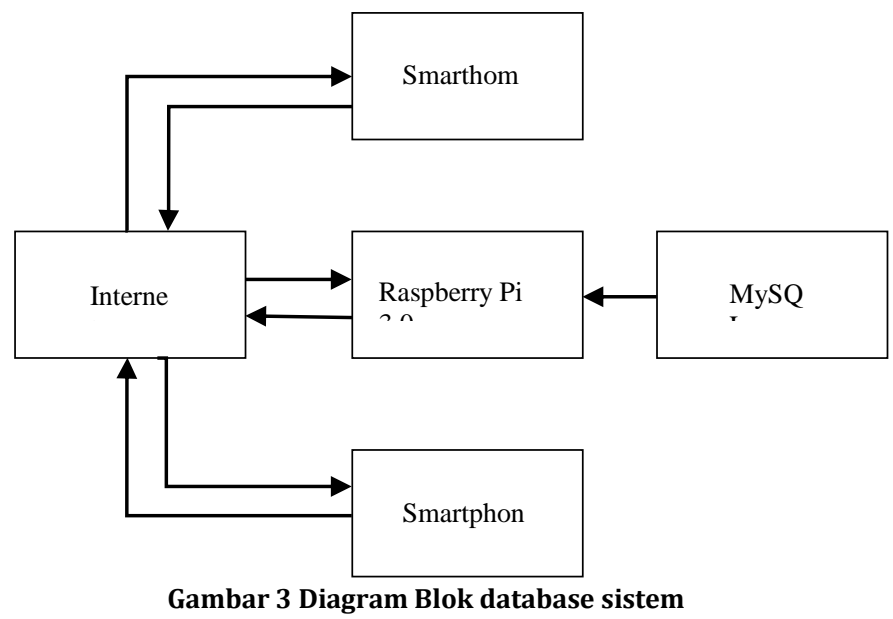

Dari Blok diagram diatas dapat dijelaskan secara singkat bahwa untuk mengakses sistem yang ada di
Smarthome diperlukan Smartphone yang terhubung ke internet kemudian setelah terhubung ke internet akan di proses dalam Raspberry Pi 3.0 yang sudah memiliki data khusus yang dikirim dari MySQL. Ketika data yang dimasukkan dalam aplikasi sesuai dengan data yang terdaftar dalam MySQL maka aplikasi dapat mengakses sistem dalam Smarthome.

\section{Perancangan Perangkat Lunak (Software)}

Dalam perancangan software untuk membantu kinerja dari Smarthome itu sendiri digunakan Raspbian dan Android Studio. Dimana Raspbian adalah sistem operasi komputer yang berbasis debian yang dibuat khusus untuk kegunaan dari Raspberry itu sendiri, sedangkan Android Studio Merupakan sebuah Integrated Development Environment (IDE) yang resmi untuk pengembangan sebuah aplikasi pada sebuah Smartphone berbasis Android.

Selain itu digunakan phpMyAdmin untuk memproses data yang ada di MySQL. Berikut perancangan perangkat lunak dalam bentuk flowchart.

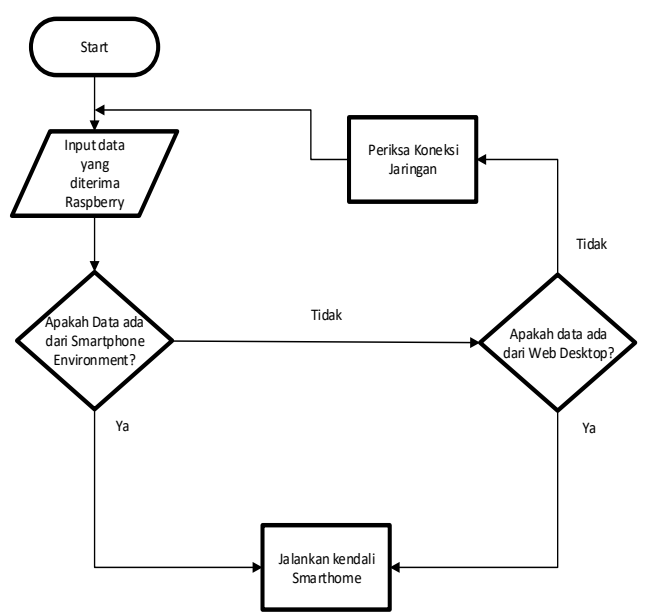

Gambar 4 Flowchart keseluruhan system

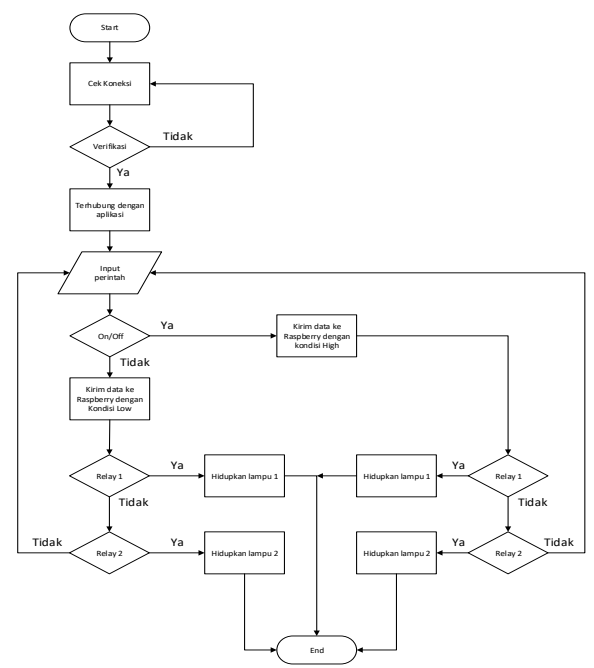

Gambar 6 Flowchart Saklar otomatis pada lampu 


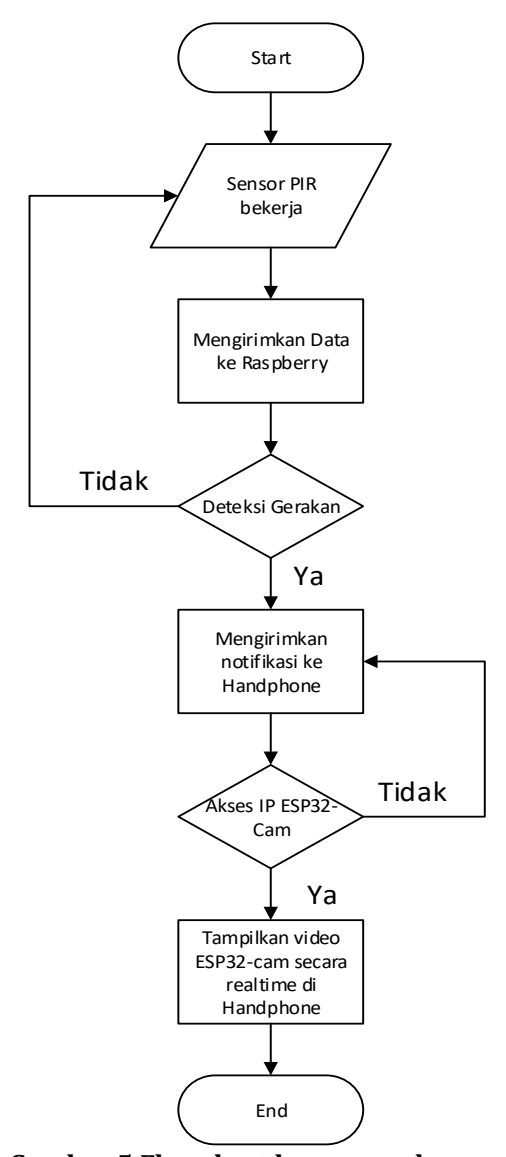

Gambar 5 Flowchart keamanan kamera

\section{HASIL DAN PEMBAHASAN}

Pada pembuatan Smart home ini dibangun menggunakan beberapa komponen yang sudah di hubungkan satu sama lainnya dan berpusat pada Raspberry pi 3.0. Berikut hasil dari perancangan perangkat keras dari keseluruhan alat.

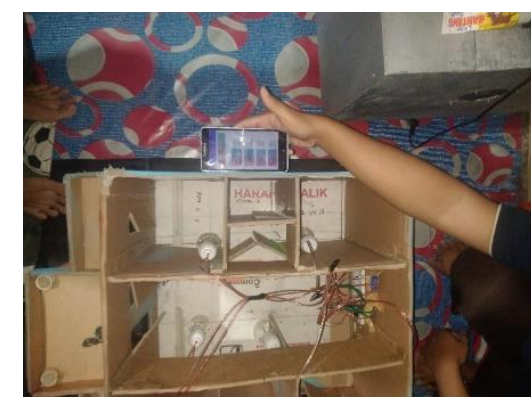

Gambar 7 perangkat keras secara keseluruhan.

Pada keseluruhan alat ketika di uji telah memberikan hasil akhir yang baik dan sesuai dengan apa yang diharapkan, dimana pada sistem Smarthome sudah berjalan dengan baik dan untuk data yang di inputkan pada database juga sudah bisa di akses dengan baik melalui aplikasi pada smartphone.

\section{Pengujian User Interface pada phpMyAdmin melalui aplikasi}

Aplikasi yang sudah dibuat dan digunakan dalam pengujian ini dibuat dengan menggunakan bahasa java menggunakan platform Android Studio. Pembuatan aplikasi tersebut sudah dihubungkan pada database yang berada di MySQL melalui phpMyAdmin.

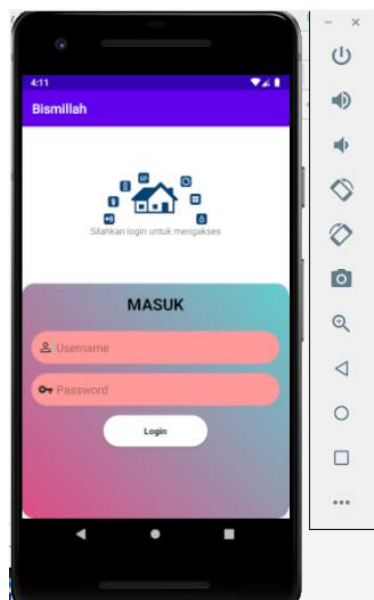

Gambar 8 data tidak terdaftar pada database MySQL

Pada gambar tersebut kita bisa lihat pada saat data username dan password tidak dimasukkan maka tidak dapat masuk ke menu utama aplikasi untuk mengontrol Smarthome, selain itu bila dimasukkan username tetapi belum terdaftar dalam database maka aplikasi pun tidak akan merespon. Sama halnya bila perangkat Smartphone tidak memiliki akses internet, aplikasi tidak akan memproses pengontrolan.

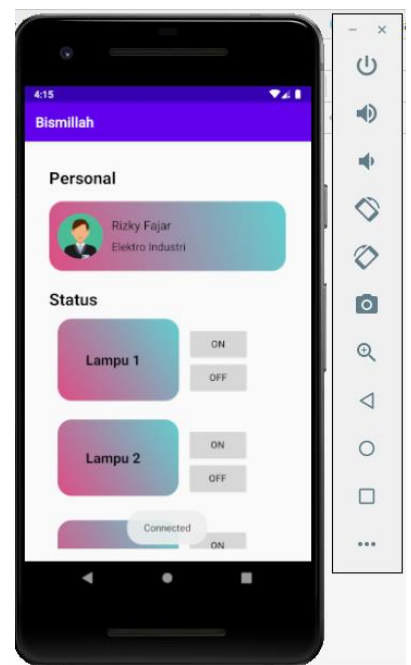

Gambar 9 data terdaftar pada database MySQL

Ketika memasukkan data dengan benar dan sudah terdaftar pada database maka akan muncul tampilan seperti Digambar setelah halaman login. Ketika masuk ke halaman beranda aka nada notifikasi pop up "Connected" artinya perangkat sudah terhubung ke seluruh sistem Smarthome yang kita miliki. 


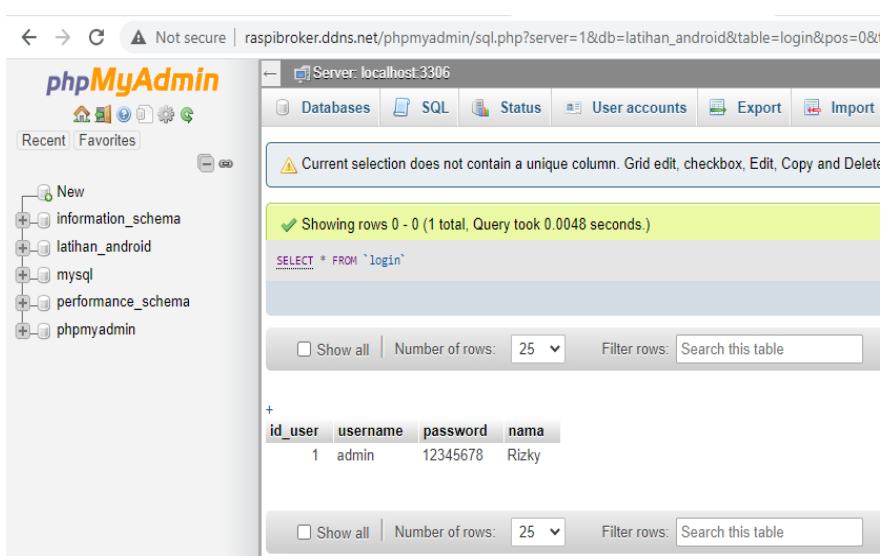

Gambar 10 data yang sudah didaftarkan pada phpMyadmin

Gambar diatas adalah contoh data yang sudah diinputkan pada phpMyAdmin, disana terlihat bahwa admin berstatus "rizky" dan pada aplikasi pun tercantum nama rizky, sehingga ketika suatu data tidak terdaftar pada phpMyAdmin output pada aplikasi akan seperti pada gambar 8.

\section{Pengujian Rangkaian Relay}

Pada pengujian ini ketika sebelumnya sudah terverifikasi bahwa user adalah pengguna yang sudah terdaftar maka proses pengontrolan saklar akan bisa dijalankan dari jarak yang jauh. Pengujian ini dapat dilihat pada gambar dibawah ini.

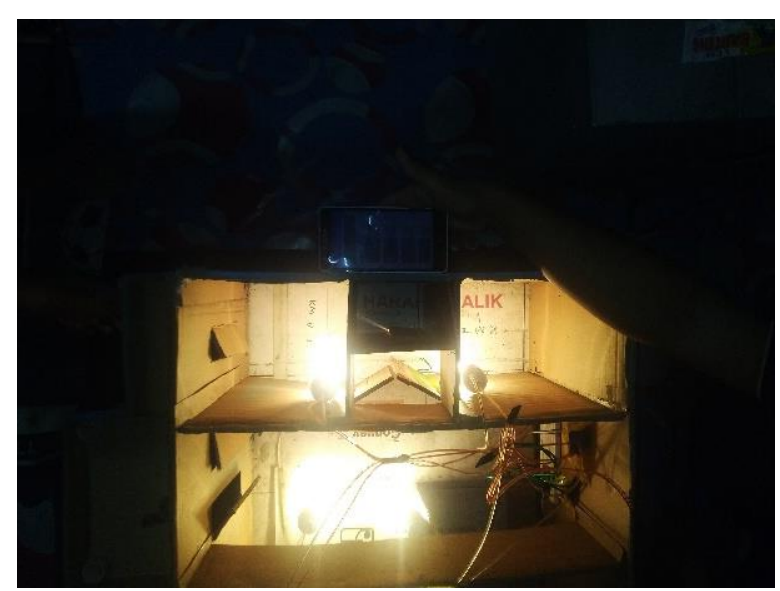

Gambar 11 Kondisi Lampu Hidup

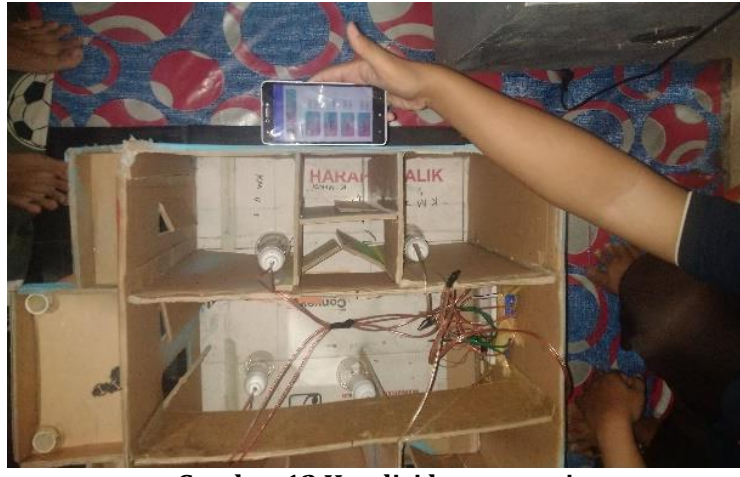

Gambar 12 Kondisi lampu mati

Pada percobaan diatas setidaknya dilakukan 3 kali percobaan dengan jarak yang jauh untuk melihat keefektifan dari perangkat dan seluruh sistem nya.

Table 1 Pengujian otomasi lampu jarak jauh

\begin{tabular}{|c|c|c|c|c|}
\hline \multirow{2}{*}{ Perangkat } & \multirow{2}{*}{$\begin{array}{c}\text { Pengujian } \\
\text { ke }\end{array}$} & \multirow{2}{*}{$\begin{array}{c}\text { Jarak } \\
(\mathrm{m})\end{array}$} & \multicolumn{2}{|c|}{ Kondisi } \\
\cline { 3 - 5 } & 1 & 10 & On & Off \\
\hline \multirow{3}{*}{ Lampu 1 } & 2 & 25 & Menyala & Mati \\
\cline { 2 - 5 } & 3 & 40 & Menyala & Mati \\
\hline \multirow{3}{*}{ Lampu 2 } & 1 & 10 & Menyala & Mati \\
\cline { 2 - 5 } & 2 & 25 & Menyala & Mati \\
\cline { 2 - 5 } & 3 & 40 & Menyala & Mati \\
\hline \multirow{3}{*}{ Lampu 3 } & 1 & 10 & Menyala & Mati \\
\cline { 2 - 5 } & 2 & 25 & Menyala & Mati \\
\hline \multirow{3}{*}{ Lampu 4 } & 3 & 40 & Menyala & Mati \\
\cline { 2 - 5 } & 2 & 10 & Menyala & Mati \\
\cline { 2 - 5 } & 3 & 25 & Menyala & Mati \\
\hline & 2 & 40 & Menyala & Mati \\
\hline
\end{tabular}

Pada pengujian diatas tidak terjadi masalah untuk jangkauan 40m, akan tetapi ada beberapa error yang terjadi jika perangkat yang digunakan tidak memiliki akses internet untuk mengakses server. Ketika itu terjadi aplikasi akan otomatis tertutup (Close). Selain itu jika perangkat Smartphone memiliki akses internet tetapi kecepatan nya lambat akan menimbulkan delay pada sistem yang membuat lampu tidak akan langsung hidup/mati, delay terlama yang tercatat adalah 10 detik.

\section{Pengujian ESP-32 CAM dan Sensor PIR}

Tidak berbeda dengan pengujian sebelumnya untuk pengujian kali ini pun akan menguji seberapa jauh perangkat dapat merespon sistem melalui Smartphone. Beberapa pengujian dilakukan untuk mendapatkan efisiensi dari aplikasi maupun perangkatnya, diantaranya sebagai berikut: 
Table 2 Pengujian Kamera Pengamanan

\begin{tabular}{|c|c|c|c|c|}
\hline $\begin{array}{c}\text { Jarak } \\
(\mathrm{m})\end{array}$ & $\begin{array}{c}\text { ESP-32 } \\
\text { CAM }\end{array}$ & $\begin{array}{l}\text { Sensor } \\
\text { PIR }\end{array}$ & Buzzer & Notifikasi \\
\hline 50 & $\begin{array}{c}\text { Ter- } \\
\text { Capture }\end{array}$ & $\begin{array}{c}\text { Terdeteksi } \\
\text { gerakan }\end{array}$ & Hidup & Terkirim \\
\hline 100 & $\begin{array}{c}\text { Ter- } \\
\text { Capture }\end{array}$ & $\begin{array}{c}\text { Terdeteksi } \\
\text { gerakan }\end{array}$ & Hidup & Terkirim \\
\hline 150 & $\begin{array}{c}\text { Ter- } \\
\text { Capture }\end{array}$ & $\begin{array}{c}\text { Terdeteksi } \\
\text { Gerakan }\end{array}$ & Hidup & Terkirim \\
\hline 200 & $\begin{array}{c}\text { Ter- } \\
\text { Capture }\end{array}$ & $\begin{array}{c}\text { Terdeteksi } \\
\text { Gerakan }\end{array}$ & Hidup & Terkirim \\
\hline 250 & $\begin{array}{c}\text { Ter- } \\
\text { Capture }\end{array}$ & $\begin{array}{c}\text { Terdeteksi } \\
\text { Gerakan }\end{array}$ & Hidup & Terkirim \\
\hline
\end{tabular}

Pada data diatas didapatkan bahwa data tidak jauh berbeda dengan pengujian pada otomasi lampu dan perangkat berjalan dengan baik. Permasalahannya pun masih sama yaitu akses internet dan data yang sudah terdaftar pada database MySQL.

\section{PENUTUP}

Berdasarkan pengujian yang telah dilakukan, dapat ditarik kesimpulan bahwa penggunaan Raspberry $\mathrm{Pi}$ sebagai server public pada database MySQL sangat efisien penggunaanya, dikarenakan dengan Raspberry Pi dapat menghemat biaya yang besar untuk penyewaan server. Pada saat pengujian login melalui aplikasi berjalan dengan baik dimana ketika dimasukan usename yang tidak tercantum di database maka aplikasi akan menolak login tersebut sehingga tidak bisa mengontrol sistem pada Smarthome.

Penggunaan database MySQL ini pun sangat membantu keamanan pada pengontrolan yang dilakukan untuk Smarthome melalui Smartphone yang user miliki. Selain itu pembuatan server public sekaligus database MySQL ini pun memudahkan user untuk mengakses sistem dari Smarthome yang dimiliki dimanapun, selama user memiliki sebuah perangkat yang tersambung ke internet.

\section{REFERENSI}

[1] R. E. Putri and D. Yendri, "Sistem Pengontrolan Dan Keamanan Rumah Pintar (Smart Home) Berbasis Android," Journal on Information Technology and Computer Engineering, 2018. .

[2] F. Masykur and F. Prasetiyowati, "Aplikasi Rumah
Pintar (Smart Home) Pengendali Peralatan

Elektronik Rumah Tangga Berbasis Web," J. Teknol. Inf. dan Ilmu Komput., vol. 3, no. 1, p. 51, 2016, doi: 10.25126/jtiik.201631156.

[3] A. Sofwan, "Belajar Mysql dengan Phpmyadmin Pendahuluan," Modul kuliah Graphical User Interface I (GUI) di Perguruan Tinggi Raharja, 2011. .

[4] A. Pratama, "Pengenalan MySQL," p. 2013, 2007, [Online]. Available: http://sigma.ac.id/pengenalanmysql.html.

[5] W. G. J. Halfond, J. Viegas, and A. Orso, "A

Classification of SQL Injection Attacks and Countermeasures," Prev. Sql Code Inject. By Comb. Static Runtime Anal., p. 53, 2008.

[6] Madcoms, "Pemrograman PHP dan MySQL unutk Pemula," p. 230, 2016.

[7] R. E. Standsyah and I. S. N.S Restu, "Implementasi PHPMyAdmin Pada Rancangan Sistem

Pengadministrasian," Unisda J. Math. Comput. Sci., vol. 3, no. 2, pp. 38-44, 2017.

[8] A. Guion, K. Burton, H. Hodgkins, and D. Morris, "Implementation Of An Interactive Database Interface Utilizing HTML, PHP, JavaScript, and MySQL In Support Of Water Quality Assessments In The Northeastern North Carolina Pasquotank Watershed," AGU Fall Meet., no. 1, pp. 1-16, 2015, [Online]. Available:

http://nia.ecsu.edu/ur/1415/teams/db/2015_mm t_Report_v_150421.pdf.

\section{Biodata Penulis}

Rizky Fajar Ramadhan, dilahirkan di kota Banjar, Jawa Barat, 06 Januari 1998. Sedang dalam masa studi di Program Studi Teknik Elektro Industri, Jurusan Teknik Elektro, Fakultas Teknik, Universitas Negeri Padang.

Riki Mukhaiyar, dilahirkan di Padang, 25 Juni 1978. Menyelesaikan S1 pada jurusan Teknik Elektro Universitas Bung Hatta tahun 2000 dan pendidikan Pascasarjana (S2) Magister Teknik bidang Teknik Elektro Institut Teknologi Bandung pada tahun 2003. Dan menyelesaikan pendidikan Doktoral (S3) pada Tahun 2015 di University of Newcastle Upon Tync jurusan Teknik Elektro. Menyelesaikan pendidikan keprofesian di Institut Teknologi Bandung pada Tahun 2016. Sejak tahun 20xx menjadi staf pengajar tetap di jurusan Teknik Elektro Fakultas Teknik Universitas Negeri Padang. 